\title{
Left atrial wall thickness and its relationship with reconnection after pulmonary vein isolation in patients with atrial fibrillation evaluated using a three-dimensional wall thickness map
}

Seil Oh ${ }^{1,2^{*}}$, Yoon Ha Joo ${ }^{2}$, Euijae Lee ${ }^{1}$, So-Ryoung Lee ${ }^{1}$, Myung-Jin Cha', Eue-Keun Choi ${ }^{1}$, Jung Chan Lee Le $^{2,3}$ and Whal Lee ${ }^{4}$

\begin{abstract}
Background: The major cause of recurrence after pulmonary vein (PV) isolation for atrial fibrillation (AF) is PV reconnection, and thicker wall could be associated with reconnection.

Objectives: This study aimed to evaluate the wall thickness of the PV antrum in reconnection sites using a threedimensional (3D) wall thickness map.

Methods: A total of 91 patients who underwent a second ablation procedure due to AF recurrence were evaluated. The locations of the PV reconnection sites were confirmed in electroanatomical maps. A 3D atrial wall thickness (AWT) map was created using computed tomography scan data. The AWT values of the ablation lines of the index procedure were graded in each segment of the PV antrum: grade 1, $0.5<$ AWT $\leq 1.0 \mathrm{~mm}$; grade 2, $1.0<$ AWT $\leq 1.5 \mathrm{~mm}$; grade 3, $1.5<$ AWT $\leq 2.0 \mathrm{~mm}$; grade 4, $2.0<$ AWT $\leq 2.5 \mathrm{~mm}$; grade 5 , AWT $>2.5 \mathrm{~mm}$.

Results: A total of 281 PV reconnection sites among 1256 segments of the PV antrum in 79 patients were detected. The average AWT grades were $2.7 \pm 1.0$ and $2.2 \pm 1.0$ in the reconnected and non-reconnected segments, respectively $(P<0.01)$. Higher AWT grades were observed in the reconnected superior segments of the left superior PV, carina and inferior segments of the left inferior PV, superior and posterior segments of the right superior PV, and posterior and inferior segments of the right inferior PV.
\end{abstract}

Conclusion: The reconnected segments of the PV antrum showed thicker myocardium than the non-reconnected ones in patients with recurrent AF after catheter ablation. A wall thickness map for PV isolation could be considered for customized ablation in order to reduce PV reconnection.

Keywords: Catheter ablation, Atrial fibrillation, Pulmonary vein, Wall thickness

*Correspondence: seil@snu.ac.kr

${ }^{1}$ Department of Internal Medicine, Seoul National University College of Medicine and Seoul National University Hospital, 101 Daehak-ro, Jongno-gu, 03080 Seoul, Republic of Korea

Full list of author information is available at the end of the article

\section{Introduction}

Atrial fibrillation (AF) is the most common sustained arrhythmia, and multiple mechanisms are involved in its pathophysiology [1]. The most important anatomical structure related to AF trigger is the pulmonary vein (PV), which was demonstrated by Haissaguerre et al's 
landmark study [2]. Based on these findings, electrical isolation of the PV is an essential part of catheter ablation for AF [3]. Despite the development of new technologies for catheter ablation, the recurrence rates after PV isolation remain relatively high. The recurrence rates range from 25 to $40 \%$ from 3 months to 1 year after PV isolation [3]. PV reconnection is a major cause of recurrence after PV isolation procedure [4, 5]. Several techniques for achieving permanent $\mathrm{PV}$ isolation have been introduced and evaluated such as the pace-and-ablate approach and adenosine-guided detection of dormant conduction [6, 7].

One of the major hurdles in the creation of transmural lesion by radiofrequency (RF) ablation is myocardial wall thickness. In a study using bipolar RF ablation in excised left atrial specimens, transmural lesion was only created in $<40 \%$ of the cases with thickness $>2.0 \mathrm{~mm}$ [8]. Mitral isthmus is one of the most common ablation targets for persistent AF and mitral isthmus-dependent atrial flutter. The thickness of the mitral isthmus is $2.05 \pm 0.47 \mathrm{~mm}$ in $60 \mathrm{AF}$ patients [9], $2.21 \pm 0.31 \mathrm{~mm}$ in $34 \mathrm{AF}$ patients [10], and $2.4 \pm 0.8 \mathrm{~mm}$ in a study using CT scan data of 140-consecutive individuals [11]. Its thickness is generally greater than that of the left atrial posterior wall in which most of PV isolation is performed $[9,10]$. Acute success rate of the mitral isthmus ablation is lower than that of PV isolation and known to be variable: 74\% [12], $81 \%$ [13], 86\%, [14] and 92\% [15]. Latcu et reported that procedure failure group had thicker isthmus than success group ( $7 \pm 3.2$ vs. $2.4 \pm 3.1 \mathrm{~mm}$ ) [13]. Furthermore, a thick PV antrum is a predictor of dormant conduction $[16,17]$ and patients with AF recurrence showed thicker $\mathrm{PV}$ antrum than AF-free patients after catheter ablation $[18,19]$. However, manual measurement of atrial wall thickness is a laborious work and intraobserver and interobserver variations are possible because of determination of the epicardial border is difficult in manual measurements.

The aim of this study was to evaluate the wall thickness of the PV antrum in reconnection sites using a threedimensional (3D) wall thickness map that could provide intuitive thickness information to physicians for convenient and reproducible assessment.

\section{Methods}

\section{Patient population}

A total of 91 consecutive patients who underwent a second ablation procedure due to $\mathrm{AF}$ recurrence after PV isolation from November 2012 to July 2019 at Seoul National University Hospital were evaluated retrospectively. Patients who did not have PV reconnection $(n=7)$, with a history of previous maze operation $(n=4)$, and with poor computed tomography (CT) scan quality due to motion artifact $(n=1)$ were excluded. This study received approval from the Institutional Review Board at Seoul National University Hospital (IRB no. 1908-0331052) and adhered to the guidelines set in the Declaration of Helsinki (2013). The study protocol was waived from informed consent for the study population owing to the retrospective nature of the study by the Institutional Review Board at Seoul National University Hospital.

\section{Electrophysiological study and index catheter ablation}

Among 79 patients, 64 patients $(81 \%)$ underwent their index procedures in Seoul National University Hospital. PV isolation was performed based on global standard practice [3]. The procedures were performed at a single center by three independent expert electrophysiologists. Ablation procedures were performed as described in our previous study [20, 21]. Briefly, patients were sedated with intravenous midazolam or propofol, and additional fentanyl was given, as needed, throughout the procedure. For vascular access, two sheaths were placed in the left femoral vein and two sheaths in the right femoral vein. The duo-decapolar and right ventricle-His bundle electrocardiogram catheters, were introduced via the left femoral vein. Left atrial instrumentation via the right femoral vein was performed with double transseptal puncture with a Brockenbrough needle, using fluoroscopy with small contrast injections for guidance. Systemic anticoagulation with intravenous heparin was initiated immediately after the transseptal puncture, with a target-activated coagulation time of $300-350 \mathrm{~s}$ that was checked every $30 \mathrm{~min}$.

Electroanatomical mapping was performed with CARTO-3 $(n=88)$ or CARTO XP $(n=3)$ mapping system (Biosense Webster, Diamond Bar, CA, USA). The electroanatomical maps of the left atria and the PVs were created to guide the ablation. A circular mapping catheter (Biosense Webster) with 2-6-2 mm spacing was used to guide and map the four PVs. Ablations were performed using open irrigation catheters (Thermocool or Thermocool SF, Biosense Webster) targeting the antrum and carina of each PV. Power level was limited to 25-35 W at anterior and $20-30 \mathrm{~W}$ at posterior sites. We used following flow rate according to power level and catheter type: $17 \mathrm{ml} / \mathrm{min}$ for Thermocool catheter and $8 \mathrm{ml} / \mathrm{min}$ for Thermocool SF catheter in case of power $<30 \mathrm{~W} ; 30 \mathrm{ml} /$ min for Thermocool catheter and $15 \mathrm{ml} / \mathrm{min}$ for Thermocool SF catheter in case of power $\geq 30 \mathrm{~W}$. Minimum ablation time per point was $20 \mathrm{~s}$. We used ablation index in 7 patients among the enrolled patients: the values of $\geq 450$ at the anterior and superior segments and of $\geq 350$ at the posterior, inferior, and carina segments, which were based on our previous study [22]. The absence of PV potentials was confirmed by remapping the $P V \geq 30 \mathrm{~min}$ 
(a)
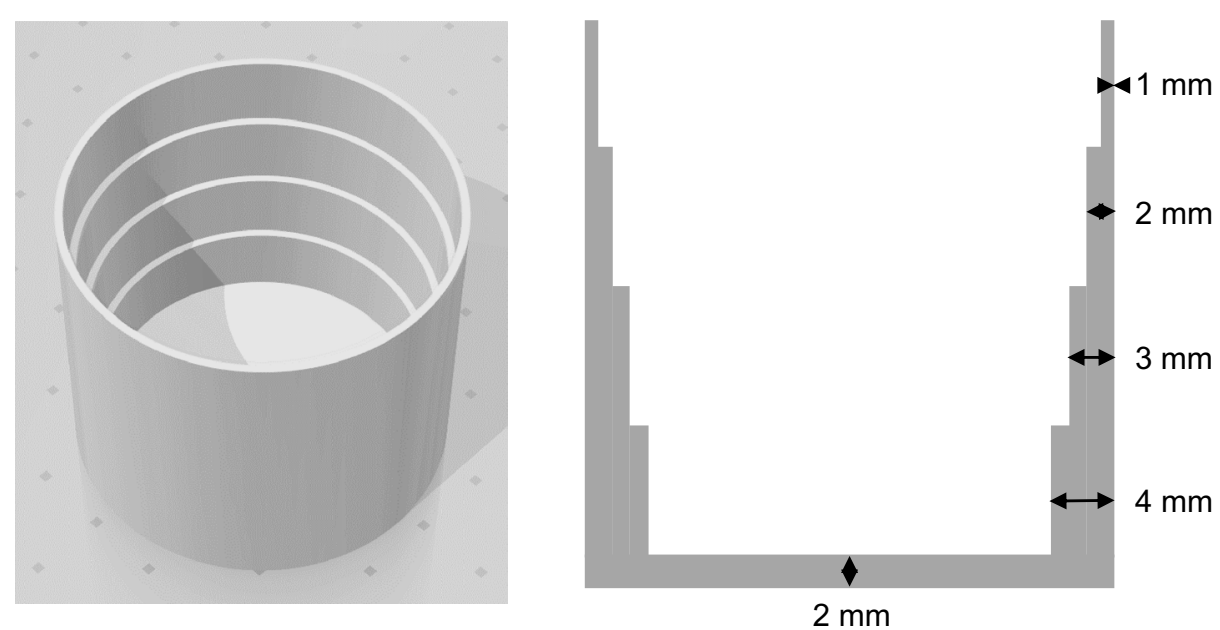

(b)



Fig. 1 Chamber phantom and its 3D wall thickness map. a Diagram of the model used in the present study. The 3D figure was generated by Inventor 2019 (Autodesk, San Rafael, CA) and the cross-sectional diagram was generated by PowerPoint 2016 (Microsoft, Redmond, WA). b 3D wall thickness map showed distinct regions with thickness of 1, 2, 3, and $4 \mathrm{~mm}$

after PV isolation. If reconnection was detected, the reconnected PVs were reisolated using additional RF energy delivery.

\section{Second electrophysiological study for re-do ablation}

In the second electrophysiological study performed after the diagnosis of AF recurrence in each patient, the locations of the PV reconnection sites were confirmed by detection of PV potentials using a circular mapping catheter with 2-6-2 mm spacing or a 5-splined mapping catheter (PentaRay; Biosense Webster) with 4-4-4 mm spacing in bipolar voltage maps created with the CARTO-3 mapping system. The mean voltage amplitudes of the gap potential in the ablation line were $0.62 \pm 0.61$ and $0.33 \pm 0.17 \mathrm{mV}$ during sinus rhythm and $\mathrm{AF}$, respectively [23]. Therefore, we adjusted the threshold amplitude for detection of reconnection site to $0.2-0.5 \mathrm{mV}$ according to the patient's rhythm. Total nine patients' voltage maps were created during AF. A reconnected segment was confirmed when it showed a gap potential at the PV antrum segment that was connected electrically with the PV potentials inside the previous ablation line. After the mapping, we performed ablation of all gap segments and deliver DC cardioversion in case of AF after the ablation. And then we created voltage map again during sinus rhythm to find the missing gaps. No segments showing gaps were found in these patients.

\section{CT scan}

Prospective ECG-triggered sequential CT was performed with a 256-channel multidetector CT (SOMATOM Force; Siemens, Munich, Germany), with a gantry rotation time of $0.25 \mathrm{~s}, 0.6-\mathrm{mm}$ slice collimation, tube voltage 
(a)


(b)

(c)
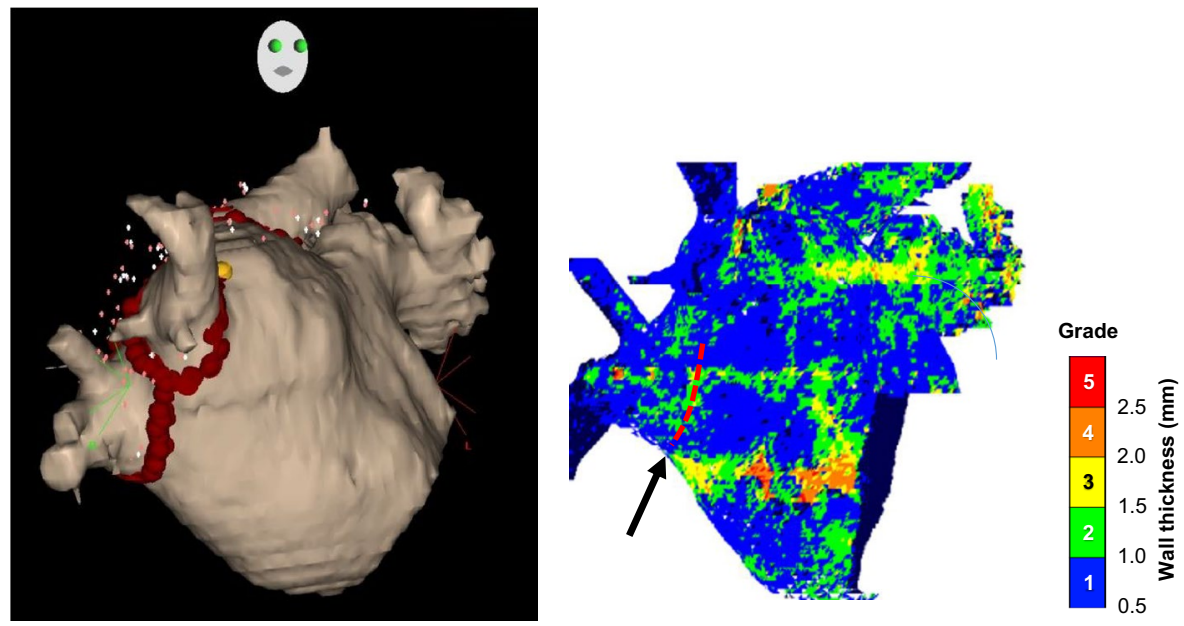

Patient \#73

Fig. 2 Analysis of ablation lines. a Classification of segments of PV antrum from endocardial view. Diagrams were generated by PowerPoint 2016 (Microsoft, Redmond, WA). Ablation line to analyze on the CARTO system $\mathbf{b}$ was matched with the wall thickness map (c). A red dashed line (arrow) indicates the ablation line on the anterior segment of RIPV antrum. Green-colored areas are the highest AWT grade with about $75 \%$ (>25\%) of the length of the ablation line, thus AWT of the anterior segment of RIPV antrum is grade 2 in this patient. LSPV left superior PV, LIPV left inferior PV, RSPV right superior PV, RIPV right inferior PV

of $70-130 \mathrm{kVp}$, and effective tube current of $266-522$ mAs using automated exposure control.

No sublingual nitroglycerine or $\beta$-blocker was given before scanning. All patients were scanned in arm abduction position and performing breath-hold technique. The scan range included the aortic arch to the bottom of the heart. Image acquisition was gated at the systolic phase, with $200-400 \mathrm{~ms}$ of RR interval. An $80-\mathrm{ml}$ bolus of iodinated intravenous contrast iomeprol $400 \mathrm{mg} / \mathrm{ml}$ (Iomeron; Bracco, Milan, Italy) was injected with a flow rate of $4.0 \mathrm{ml} / \mathrm{s}$, and the bolus tracking region of interest (ROI) was placed in the descending aorta. Early-phase images were acquired $10 \mathrm{~s}$ after the attenuation in the ROI reached 100 Hounsfield units (HU). Three-minute delayed-phase images were also acquired for the evaluation of presence of thrombus at the left atrial appendage.

Early-phase images were reconstructed with slice thickness and increment of $3 / 3 \mathrm{~mm}$ and $0.75 / 0.5 \mathrm{~mm}$, respectively. Three-minute delayed-phase images were reconstructed with slice thickness and increment of $3 / 3 \mathrm{~mm}$ and $0.75 / 0.7 \mathrm{~mm}$, respectively. Two-chamber, short-axis, four-chamber, axial-view, and volume-rendering images were reconstructed. 
Table 1 Demographics of enrolled patients

\begin{tabular}{|c|c|}
\hline & Total $(n=79)$ \\
\hline Age (years) & $60 \pm 9.4$ \\
\hline Men & $65(82 \%)$ \\
\hline Height $(\mathrm{cm})$ & $168 \pm 8.41$ \\
\hline Weight (kg) & $70.0 \pm 10.7$ \\
\hline Body mass index $\left(\mathrm{kg} / \mathrm{m}^{2}\right)$ & $24.7 \pm 2.47$ \\
\hline Paroxysmal AF & $50(63 \%)$ \\
\hline LV ejection fraction (\%) & $58 \pm 6.9$ \\
\hline LA volume index $\left(\mathrm{ml} / \mathrm{m}^{2}\right)$ & $45 \pm 16$ \\
\hline Heart failure & $11(14 \%)$ \\
\hline Hypertension & $35(44 \%)$ \\
\hline Diabetes mellitus & $16(20 \%)$ \\
\hline Cerebral infarction/transient ischemic attack & $5(6.3 \%)$ \\
\hline Chronic kidney disease & $9(11 \%)$ \\
\hline \multicolumn{2}{|l|}{ Medications } \\
\hline ACEI/ARB & $20(25 \%)$ \\
\hline Beta blocker & $22(28 \%)$ \\
\hline Calcium channel blocker & $24(30 \%)$ \\
\hline Oral anticoagulants & 79 (100\%) \\
\hline Warfarin & $26(33 \%)$ \\
\hline NOAC & $53(67 \%)$ \\
\hline Antiarrhythmic drugs & $71(90 \%)$ \\
\hline Class IC & $49(62 \%)$ \\
\hline Class III & 22 (28\%) \\
\hline
\end{tabular}

$A C E l$ angiotensin converting enzyme inhibitor, $A F$ atrial fibrillation, $A R B$ angiotensin II receptor blocker, $L A$ left atrium, $L V$ left ventricle, NOAC nonvitamin $\mathrm{K}$ antagonist oral anticoagulants

\section{Reconstruction of 3D left atrial wall thickness map}

We developed a custom software using MATLAB R2018b (MathWorks, Natick, MA, USA) for the reconstruction of a 3D left atrial wall thickness (AWT) map. The AWT map was reconstructed using the DICOM format of CT scan data obtained for the index ablation procedure. Briefly, the left atrium (LA) was manually cropped. Blood-pooled area was determined by adjusting the lower and upper limits of the $\mathrm{HU}$ level, which varied among patients. The usual lower and upper limits were 300 and $700 \mathrm{HU}$, respectively.

Atrial wall segmentation was performed based on the method reported by Bishop et al [24]. We modified their method as follows: The first two layers were formed by adding 2 pixels from the endocardial border if they had an $\mathrm{HU}$ value between 0 and the upper limit of the blood-pooled region (600-900 HU, mostly $700 \mathrm{HU}$, as described above). The additional layers were then added by dilation if the $\mathrm{HU}$ value ranged from 0 to the upper limit for the atrial myocardium (100-120 HU, mostly $100 \mathrm{HU})$. This step was repeated 5 times. The final image was eroded by 1 pixel and then dilated by 1 pixel to remove noise.
Based on the endocardial border, triangular meshes were created. They had an area of approximately 0.7 $\mathrm{mm}^{2}$, which was dependent on the size of the CT scan image of each patient. From the triangle center of each mesh, a normal vector was calculated. The thickness was calculated from the distance from the mesh center to the closest point in the epicardial border from the point that meets the normal vector. The $3 \mathrm{D}$ model of the endocardial meshes was visualized by color codes depending on thickness.

\section{Evaluation using a chamber phantom}

We evaluated the accuracy of the software using a cupshaped chamber phantom with regions of thickness of 1 , 2, 3, and $4 \mathrm{~mm}$ (Fig. 1). The model was made of polylactic acid and generated by a $3 \mathrm{D}$ printer with a resolution of $0.1 \mathrm{~mm}$. The chamber phantom was filled with diluted iodinated intravenous contrast, and then, it was placed in a $0.9 \%$ saline bath. CT scanning was performed with $70 \mathrm{kVp}$ and automatic exposure control. A wall thickness map was created using the method described above.

Assessment of the wall thickness of the ablation regions of the PV antrum.

We classified the segments of the PV antrum as follows: carina and superior, anterior, posterior segments of the left and right superior PVs (LSPV and RSPV, respectively); carina and anterior, posterior, and inferior segments of the left and right inferior PVs (LIPV and RIPV, respectively) (Fig. 2a).

The wall thickness of an ablation region was graded in each segment as follows: grade 1, $0.5<\mathrm{AWT} \leq 1.0 \mathrm{~mm}$; grade $2,1.0<\mathrm{AWT} \leq 1.5 \mathrm{~mm}$; grade $3,1.5<\mathrm{AWT} \leq 2.0 \mathrm{~mm} ;$ grade $4,2.0<\mathrm{AWT} \leq 2.5 \mathrm{~mm}$; grade $5, \mathrm{AWT}>2.5 \mathrm{~mm}$. A different color code was assigned to each AWT grade for intuitive understanding. A thick PV antral region was defined as grade 3 or higher (AWT > $1.5 \mathrm{~mm}$ ).

Ablation line on the CARTO system was matched with the same projection view of the wall thickness map (Fig. 2b, c). Two physicians (SO and EL) compared electroanatomical map and wall thickness map using en-face view of each ablation line and visually determined the location of each ablation region on wall thickness maps.

The AWT grade of the ablation region was determined by the highest AWT grade with more than $25 \%$ of the length of the ablation line of the segment (Fig. 2b, c). In case of two carina lines created in the PVs, the AWT grade of the carina was determined separately, one for the superior vein and one for the inferior vein.

\section{Prominent myofibers in the LA}

Numerous atrial myofibers were previously described $[25,26]$. We analyzed them in the 3D AWT maps 
(a)

a)

\section{AWT Grade of All 1256 Ablation Regions}

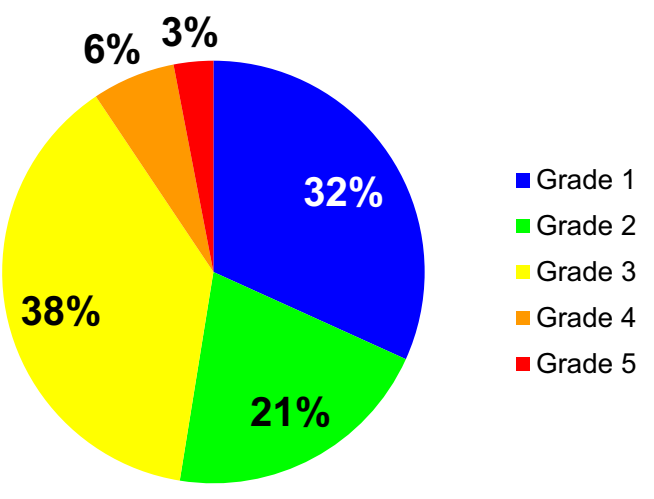

(b) AWT Grade of Ablation Regions of Each PV Antrum

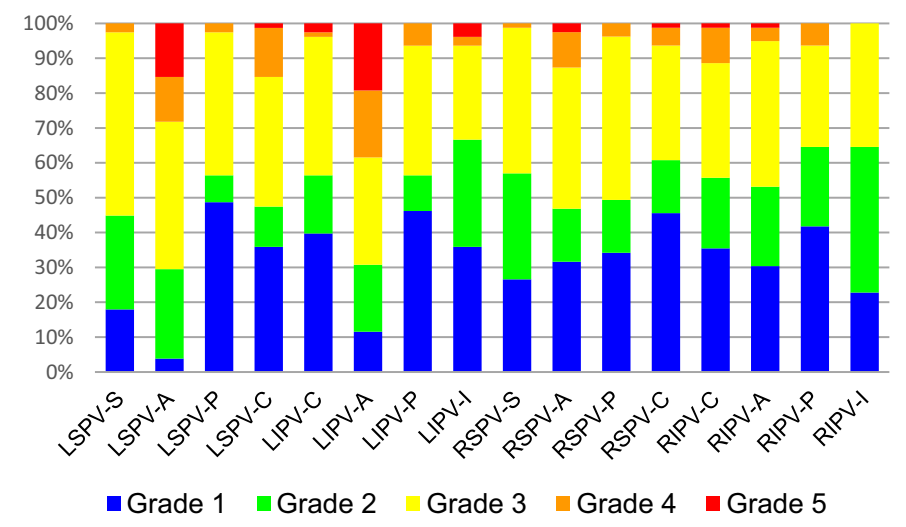

(c)

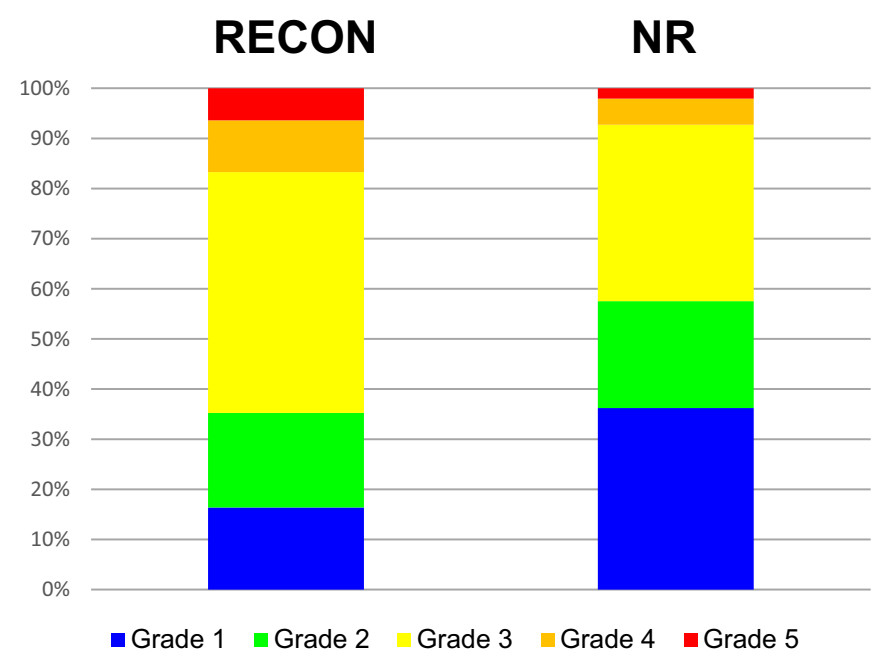

Fig. 3 Atrial wall thickness of PV antrum. Distribution of AWT grades of overall 1256 ablation segments (a) and ablation segments of each PV antrum (b). -S, superior segment (e.g., LSPV-S, superior segment of LSPV); -A, anterior segment; -P, posterior segment; -C, carina segment; -I, inferior segment. c Distribution of AWT grades. AWT atrial wall thickness, RECON reconnected segments, NR non-reconnected segments. All diagrams were generated by Excel 2016 (Microsoft, Redmond, WA). 
Table 2 Reconnected pulmonary veins and their segments in 79 patients

\begin{tabular}{llr}
\hline PV (No. of reconnected PVs) & No. of reconnected segments \\
\hline LSPV (46) & Superior & 16 \\
& Anterior & 28 \\
& Posterior & 15 \\
& Carina & 18 \\
LIPV (42) & Carina & 13 \\
& Anterior & 20 \\
& Posterior & 11 \\
& Inferior & 7 \\
RSPV (52) & Superior & 19 \\
& Anterior & 20 \\
& Posterior & 20 \\
& Carina & 14 \\
RIPV (53) & Carina & 23 \\
& Anterior & 14 \\
& Posterior & 24 \\
& Inferior & 19 \\
\hline
\end{tabular}

$P V$ pulmonary vein, $L S P V$ left superior pulmonary vein, $L I P V$ left inferior pulmonary vein, $R S P V$ right superior pulmonary vein, $R I P V$ right inferior pulmonary vein

Table 3 Atrial wall thickness grade of reconnected vs. nonreconnected $\mathrm{PV}$ segments

\begin{tabular}{llll}
\hline Group & RECON & NR & P value \\
\hline AWT grade & $\begin{array}{l}2.7 \pm 1.0 \\
\text { (281 segments) }\end{array}$ & $\begin{array}{l}2.2 \pm 1.0 \\
(975 \text { segments) }\end{array}$ & $<0.01$ \\
Distribution of & & & $<0.0001$ \\
AWT grade & & 353 & \\
Grade 1 & 46 & 208 & \\
Grade 2 & 53 & 343 & \\
Grade 3 & 135 & 51 & \\
Grade 4 & 29 & 20 & \\
Grade 5 & 18 &
\end{tabular}

$A W T$ atrial wall thickness, $R E C O N$ reconnected, $N R$ non-reconnected

according to their location and orientation based on the previous reports. Prominent regions were regions that were thicker by one or more AWT grades than the surrounding regions and were thus clearly detected in colorcoded 3D maps.

\section{Statistical analysis}

Continuous variables are presented as mean \pm standard deviation, and categorical variables are presented as absolute values and percentages. For the comparison, continuous variables were evaluated by Student $t$ tests, and categorical variables were evaluated by the Chi-square test. $\mathrm{P}<0.05$ was considered as statistically significant. These analyses were performed using $\mathrm{R}$ (version 3.4.3, The R Foundation, Vienna, Austria).

\section{Results \\ Wall thickness of the chamber phantom}

The overall average thickness of the phantom was $2.0 \mathrm{~mm}$, which was calculated geometrically. The wall thickness map showed that the average thickness of 18,459 meshes was $1.8 \mathrm{~mm}$. The created wall thickness map also showed distinct regions of different thickness, but it had inevitable noise artifacts of the CT scan (Fig. 1b).

\section{Wall thickness of the reconnected PV antrum}

One case of common left PV (LPV) was detected; therefore, right PV (RPV) antrum segments were only analyzed in this particular patient. Two carina lines were created in 19 LPVs and 21 RPVs in the index ablation procedures. Finally, a total of 1256 segments of 314 PVs in 79 patients were analyzed. The clinical characteristics of these patients are summarized in Table 1. The overall distribution of the AWT grade of a total of 1256 segments and the segments of each PV are shown in Fig. 3a and b.

A total of 191 PVs were reconnected, and the average number of reconnected PVs was $2.4 \pm 1.0$ per patient. Reconnection was observed in 46 LSPVs (58\%), 42 LIPVs (53\%), 52 RSPVs (66\%), and 53 RIPVs (67\%) among 79 patients (Table 2). A total of $281 \mathrm{PV}$ reconnection sites were detected, and one reconnected PV had an average of 1.5 reconnected segments.

The average AWT grades were $2.7 \pm 1.0$ and $2.2 \pm 1.0$ in the reconnected and non-reconnected segments, respectively $(\mathrm{P}<0.01)$. A thick $\mathrm{PV}$ antral region $(\geq$ grade $3)$ was detected in 182 reconnection sites (65\%). The distribution of the AWT grades is presented in Table 3 and Fig. 3c. Higher AWT grades were observed in the reconnected superior segments of the LSPV, carina and inferior segments of the LIPV, superior and posterior segments of the RSPV, and posterior and inferior segments of the RIPV (Tables 4 and 5).

\section{Prominent myofibers in the LA}

Representative examples of prominent myofibers are shown in Fig. 4a-h. The RPV posterior bundle was the prominent region of the LA posterior wall adjacent to the posterior portion of the RPV antrum (Fig. 4b). The RPV carina bundle was the prominent linear region in the RPV carina (Fig. 4c). The septopulmonary bundle was the prominent region from the interatrial septum to the LA roof near the superior portion of the RSPV (Fig. 4d). The 
Table 4 Wall thickness of left PV antrum

\begin{tabular}{|c|c|c|c|c|c|c|c|c|}
\hline \multicolumn{9}{|l|}{ Left superior PV } \\
\hline \multirow{2}{*}{$\begin{array}{l}\text { Segment } \\
\text { Group (number) }\end{array}$} & \multicolumn{2}{|l|}{ Superior } & \multicolumn{2}{|l|}{ Anterior } & \multicolumn{2}{|l|}{ Posterior } & \multicolumn{2}{|l|}{ Carina } \\
\hline & RECON (16) & NR (62) & RECON (28) & NR (50) & RECON (15) & NR (63) & RECON (18) & NR (60) \\
\hline Grade & $2.9 \pm 0.5^{* *}$ & $2.3 \pm 0.8$ & $3.1 \pm 1.2$ & $3.1 \pm 1.0$ & $2.3 \pm 1.0$ & $1.9 \pm 1.0$ & $2.6 \pm 1.0$ & $2.3 \pm 1.2$ \\
\hline \multicolumn{9}{|l|}{ Distribution } \\
\hline Grade 1 & $0(0 \%)$ & $14(23 \%)$ & $2(7 \%)$ & $1(2 \%)$ & $5(33 \%)$ & $33(52 \%)$ & $4(22 \%)$ & $24(40 \%)$ \\
\hline Grade 2 & $3(19 \%)$ & $18(29 \%)$ & $7(25 \%)$ & $13(26 \%)$ & $1(7 \%)$ & $5(8 \%)$ & $3(17 \%)$ & $6(10 \%)$ \\
\hline Grade 3 & $12(75 \%)$ & $29(47 \%)$ & $9(32 \%)$ & $24(48 \%)$ & $9(60 \%)$ & $23(37 \%)$ & $8(44 \%)$ & $21(35 \%)$ \\
\hline Grade 4 & $1(6 \%)$ & $1(2 \%)$ & $5(18 \%)$ & $2(4 \%)$ & $0(0 \%)$ & $2(3 \%)$ & $3(17 \%)$ & $8(13 \%)$ \\
\hline Grade 5 & $0(0 \%)$ & $0(0 \%)$ & $5(18 \%)$ & $0(0 \%)$ & $0(0 \%)$ & $0(0 \%)$ & $0(0 \%)$ & $1(2 \%)$ \\
\hline$P$ value & $0.00072^{* *}$ & & 0.82 & & 0.21 & & 0.32 & \\
\hline \multicolumn{9}{|l|}{ Left inferior PV } \\
\hline Segment & \multicolumn{2}{|l|}{ Carina } & \multicolumn{2}{|l|}{ Anterior } & \multicolumn{2}{|l|}{ Posterior } & \multicolumn{2}{|l|}{ Inferior } \\
\hline Group (number) & RECON (13) & NR (65) & RECON (20) & NR (58) & RECON (11) & NR (67) & RECON (7) & NR (71) \\
\hline Grade & $2.7 \pm 0.9^{*}$ & $2.0 \pm 1.0$ & $3.5 \pm 1.4$ & $3.1 \pm 1.2$ & $2.5 \pm 1.1$ & $2.0 \pm 1.0$ & $3.3 \pm 1.4^{*}$ & $2.0 \pm 0.9$ \\
\hline \multicolumn{9}{|l|}{ Distribution } \\
\hline Grade 1 & $2(15 \%)$ & $29(45 \%)$ & $1(5 \%)$ & $8(14 \%)$ & $3(26 \%)$ & 33 (49\%) & $1(14 \%)$ & $27(38 \%)$ \\
\hline Grade 2 & $1(8 \%)$ & $12(18 \%)$ & $5(25 \%)$ & $10(17 \%)$ & $2(18 \%)$ & $6(9 \%)$ & $0(0 \%)$ & $24(34 \%)$ \\
\hline Grade 3 & $9(69 \%)$ & $22(34 \%)$ & $5(25 \%)$ & 19 (33\%) & $4(36 \%)$ & 25 (37\%) & $4(57 \%)$ & 17 (24\%) \\
\hline Grade 4 & $1(8 \%)$ & $0(0 \%)$ & $2(10 \%)$ & $13(22 \%)$ & $2(18 \%)$ & $3(4 \%)$ & $0(0 \%)$ & $2(3 \%)$ \\
\hline Grade 5 & $0(0 \%)$ & $2(3 \%)$ & $7(35 \%)$ & $8(14 \%)$ & $0(0 \%)$ & $0(0 \%)$ & $2(29 \%)$ & $1(1 \%)$ \\
\hline$P$ value & $0.02^{*}$ & & 0.26 & & 0.2 & & $0.04^{*}$ & \\
\hline
\end{tabular}

RECON reconnected, $N R$ non-reconnected

${ }^{*} \mathrm{P}<0.05$ for reconnected vs. non-reconnected

${ }^{*}$ P $\mathrm{P}<0.01$ for reconnected vs. non-reconnected

LA posterior bundle was the vertically oriented prominent region of the mid-portion of the LA posterior wall (Fig. 4e). In some patients, the RPV and LA posterior bundles were indistinguishable and combined. The LPV carina bundle was the prominent linear region in the LPV carina (Fig. 4f). The LSPV superior bundle was the bandlike prominent region near the superior portion of the LSPV antrum (Fig. 4g). Among 79 patients, prominent Bachmann's bundles and myofibers around the RPVs were frequently observed: Bachmann's bundle $(n=79$, $100 \%)$, RPV posterior bundle $(n=45,60 \%)$, RPV carina bundle $(n=44,56 \%)$, septopulmonary bundle $(n=42$, $53 \%)$, LA posterior bundle ( $n=38,48 \%)$, LPV carina bundle $(n=28,35 \%)$, LSPV superior bundle $(n=21,27 \%)$.

\section{Discussion}

The transmurality of RF ablation lesion is known to be lower in thick myocardium [8]. Therefore, the wall thickness of the PV antrum could be a determinant of successful PV isolation. The relationship between AWT and the acute success rate of PV isolation was demonstrated in studies for dormant conduction from Okumura's laboratory $[16,17]$. In these reports, the investigators manually measured AWT using CT scan. Sites with dormant conduction showed thicker myocardium (0.94 vs. $0.86 \mathrm{~mm})$ in the report of Takahashi et al., [16] even though the difference was less than $0.1 \mathrm{~mm}$. Suenari et al. reported thickness of the PV antrum in patients underwent catheter ablation for AF [27]. They measured thickness from 64-slice multidetector $\mathrm{CT}$ scan, and thickness range was $1.69-1.86 \mathrm{~mm}$ and $1.81-2.04 \mathrm{~mm}$ in left PV and right PV antrum, respectively. In their report, there were no significant differences in PV antrum thickness between AF-free vs. AF recurrence group. However, Inoue et reported that AF recurrence group showed thicker PV antrum (overall $1.6 \pm 0.6$ vs. $1.5 \pm 0.5 \mathrm{~mm}$ ) [18]. In addition, Nakatani et al. reported similar results that average $\mathrm{PV}$ antrum thickness was $1.59 \pm 0.13$ vs. $1.50 \pm 0.15$ in AF recurrence vs. no recurrence group after catheter ablation [19].

Manual measurement of AWT is labor-intensive. Furthermore, intraobserver and interobserver variations 
Table 5 Wall thickness of right PV antrum

\begin{tabular}{|c|c|c|c|c|c|c|c|c|}
\hline \multicolumn{9}{|l|}{ Right superior PV } \\
\hline \multirow{2}{*}{$\begin{array}{l}\text { Segment } \\
\text { Group (number) }\end{array}$} & \multicolumn{2}{|l|}{ Superior } & \multicolumn{2}{|l|}{ Anterior } & \multicolumn{2}{|l|}{ Posterior } & \multicolumn{2}{|l|}{ Carina } \\
\hline & RECON (19) & NR (60) & RECON (20) & NR (59) & RECON (20) & NR (59) & RECON (14) & NR (65) \\
\hline Grade & $2.6 \pm 0.8^{*}$ & $2.0 \pm 0.8$ & $2.8 \pm 1.4$ & $2.2 \pm 1.0$ & $2.6 \pm 1.0^{*}$ & $2.1 \pm 0.9$ & $2.6 \pm 1.2$ & $1.9 \pm 1.0$ \\
\hline \multicolumn{9}{|l|}{ Distribution } \\
\hline Grade 1 & $2(11 \%)$ & $19(32 \%)$ & $6(30 \%)$ & $19(32 \%)$ & $4(10 \%)$ & $23(39 \%)$ & $3(21 \%)$ & $33(51 \%)$ \\
\hline Grade 2 & $4(21 \%)$ & $20(33 \%)$ & $2(10 \%)$ & $10(17 \%)$ & $3(15 \%)$ & $9(15 \%)$ & $3(21 \%)$ & $9(14 \%)$ \\
\hline Grade 3 & $12(63 \%)$ & $21(35 \%)$ & $5(25 \%)$ & $27(46 \%)$ & $10(50 \%)$ & $27(46 \%)$ & $6(43 \%)$ & $20(31 \%)$ \\
\hline Grade 4 & $1(5 \%)$ & $0(0 \%)$ & $5(25 \%)$ & $3(5 \%)$ & $3(15 \%)$ & $0(0 \%)$ & $1(7 \%)$ & $3(5 \%)$ \\
\hline Grade 5 & $0(0 \%)$ & $0(0 \%)$ & $2(10 \%)$ & $0(0 \%)$ & $0(0 \%)$ & $0(0 \%)$ & $1(7 \%)$ & $0(0 \%)$ \\
\hline$P$ value & $0.0062^{* *}$ & & 0.14 & & $0.04^{*}$ & & 0.06 & \\
\hline \multicolumn{9}{|l|}{ Right inferior PV } \\
\hline \multirow{2}{*}{$\begin{array}{l}\text { Segment } \\
\text { Group (number) }\end{array}$} & \multicolumn{2}{|l|}{ Carina } & \multicolumn{2}{|l|}{ Anterior } & \multicolumn{2}{|l|}{ Posterior } & \multicolumn{2}{|l|}{ Inferior } \\
\hline & RECON (23) & NR (56) & RECON (14) & NR (65) & RECON (24) & NR (55) & RECON (19) & NR (60) \\
\hline Grade & $2.5 \pm 1.2$ & $2.1 \pm 1.0$ & $2.6 \pm 0.8$ & $2.1 \pm 1.0$ & $2.5 \pm 0.8^{* *}$ & $1.8 \pm 1.0$ & $2.5 \pm 0.6^{*}$ & $2.0 \pm 0.8$ \\
\hline \multicolumn{9}{|l|}{ Distribution } \\
\hline Grade 1 & $6(26 \%)$ & 22 (39\%) & $2(14 \%)$ & 22 (34\%) & $4(17 \%)$ & $29(53 \%)$ & $1(5 \%)$ & 17 (28\%) \\
\hline Grade 2 & $4(17 \%)$ & 12 (21\%) & $2(14 \%)$ & 16 (25\%) & $5(21 \%)$ & 13 (24\%) & $8(42 \%)$ & 25 (42\%) \\
\hline Grade 3 & $9(39 \%)$ & 17 (30\%) & $9(64 \%)$ & 24 (37\%) & $14(58 \%)$ & $9(16 \%)$ & $10(53 \%)$ & 18 (30\%) \\
\hline Grade 4 & $3(13 \%)$ & $5(9 \%)$ & $1(7 \%)$ & $2(3 \%)$ & $1(4 \%)$ & $4(7 \%)$ & $0(0 \%)$ & $0(0 \%)$ \\
\hline Grade 5 & $1(4 \%)$ & $0(0 \%)$ & $0(0 \%)$ & $1(2 \%)$ & $0(0 \%)$ & $0(0 \%)$ & $0(0 \%)$ & $0(0 \%)$ \\
\hline$P$ value & 0.13 & & 0.06 & & $0.0016^{* *}$ & & $0.011^{*}$ & \\
\hline
\end{tabular}

$R E C O N$ reconnected, NR non-reconnected

${ }^{*} \mathrm{P}<0.05$ for reconnected vs. non-reconnected

${ }^{* *} \mathrm{P}<0.01$ for reconnected vs. non-reconnected

are possible during measurements, unless they are performed automatically. Our technique could perform automatic measurement and provide reproducible and more reliable 3D reconstructed maps to physicians. In our study, the reconnected segments showed higher AWT grade (2.7 vs. 2.2). When we consider that AWT grade 2 indicates $1.0<\mathrm{AWT} \leq 1.5 \mathrm{~mm}$ and grade 3 indicates $1.5<\mathrm{AWT} \leq 2.0 \mathrm{~mm}$, the thickness measured in the present study seems slightly thicker than that reported by Takahashi et al [16]. In the present study, the difference in the AWT grade was 0.5 , which translates to an average thickness of $0.25 \mathrm{~mm}$ between the reconnected and nonreconnected sites.

The state-of-the-art strategies for PV isolation are used according to the ablation lesion sets: For example, circumferential ablation is used around the RPV and LPV, whereas additional linear ablation is used for lesions (carina lines) between the superior and inferior PVs [3]. According to the present study, one of the most common reconnected segments was the carina, especially in the LSPV and RIPV (Table 2). A total of 18 carina lines
(39\%) were reconnected in 46 reconnected LSPVs, and 13 carina lines (31\%) were reconnected in 42 reconnected LIPVs, 14 carina lines $(27 \%)$ were reconnected in 52 reconnected RSPVs, and 23 carina lines $(43 \%)$ were reconnected in 53 reconnected RIPVs. Therefore, ablation of the carina line might be included in an essential lesion set. Even though we didn't have yet any evidence confirmed by randomized clinical trial that additional carina line is superior to PV isolation only, carina could be an important recurrence site after PV isolation according to the previous reports. Non-isolation of the PV carina after a successful PV isolation was an independent predictor of AF recurrence [28]. Dormant PVs were reisolated at the carina region in the right PVs $(23 \%)$ and left PVs (26\%) [29].

Anterior segments of LSPV and LIPV were the thickest PV antral segments in the present study. These regions are known as ridge and ligament of Marshall area. Interesting part is that there were no significant differences between reconnected vs. non-reconnected groups in thickness grades of those segments. This may suggest 

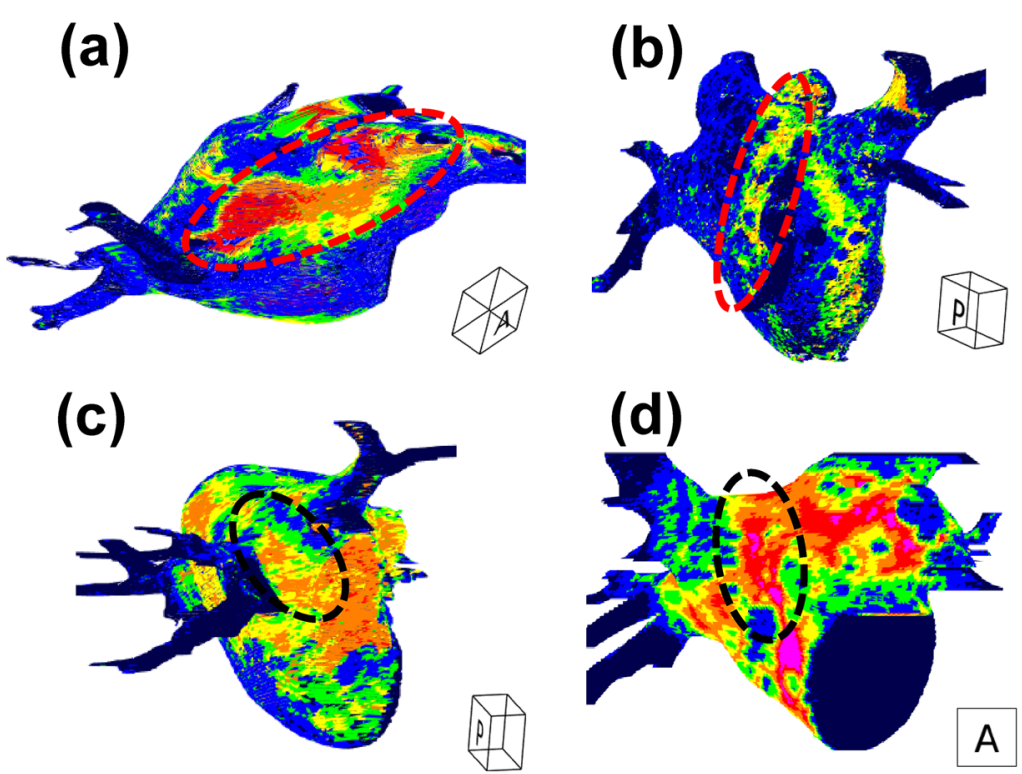

(e)


Fig. 4 Prominent myofibers in the left atria. Representative examples are indicated with dashed lines. a Bachmann's bundle (RAO cranial view). b RPV posterior bundle (RPO cranial view). c RPV carina bundle (RPO cranial view). $\mathbf{d}$ Septopulmonary bundle (AP view). e LA posterior bundle (PA view). $\mathbf{f} \angle P V$ carina bundle ( $L P O$ view). $\mathbf{g} L S P V$ superior bundle (RAO view). $\mathbf{h}$ septoatrial bundle (RAO view). AP anterior-posterior, $A W T$ atrial wall thickness, $P A$ posterior-anterior; $L P O$ left posterior oblique; $L P V$ left PV, LSPV left superior $P V, R A O$ right anterior oblique, $R P O$ right posterior oblique, RPV right PV

that other factors such as catheter stability affect reconnection in generally thick myocardium.

In addition, a customized ablation approach could have the strategy of more RF energy for thicker segments, especially in the superior segments of the LSPV, carina and inferior segments of the LIPV, superior and posterior segments of the RSPV, and posterior and inferior segments of the RIPV. We have several options for achieving this, such as monitoring of the impedance curve during ablation, higher power, longer duration, or higher ablation index. The anterior segments of the LPV, the so-called ridge area, are the thickest parts among 
the PV antrum segments. However, there was no significant difference in AWT between the reconnected and non-reconnected ridges. This means that AWT could be an indicator of successful ablation for areas with variable thickness, but not for areas with usually thick myocardium.

One of the most important hurdles in AWT measurement is epicardial border detection. We set thresholds of $0-100 \mathrm{HU}$ for the most atrial myocardium, but the HU value of the myocardium is dependent on the contrast intensity of the adjacent blood-pooled chamber, tube voltage of CT scanning, and so on. The usual HU range for skeletal muscle is known to be 0 to $100 \mathrm{HU}$ or -29 to $150 \mathrm{HU}$ [30]. For the left ventricular myocardium in the multidetector CT scan, the mean myocardial signal density was $53.5 \pm 35.1 \mathrm{HU}$ at the posterobasal segment and $97.4 \pm 17.3 \mathrm{HU}$ at the basal, mid-, and apical myocardia [31]. If we consider that the signal density of the left ventricle must be higher than that of the atria due to the higher degree of myocardial perfusion through the coronary arteries, a signal density ranging from 0 to $100 \mathrm{HU}$ would be appropriate thresholds for the atrial myocardium. In addition, results of the previous 3D-map study showed that $\mathrm{HU}$ values for epicardial thresholds were in this range [18]. Due to lower spatial resolution than CT scan, MRI was not widely studied in atrial wall thickness evaluation despite its better capability of soft tissue characterization which could be superior in epicardial border detection. Varela et al. reported novel MRI technique that enabled atrial wall thickness in good agreement with CT scan data: LA wall thickness $2.4 \pm 0.7 \mathrm{~mm}$ [32]. This technique could be a promising one in the future because of no radiation hazard in comparison with CT scan.

Ablation parameters for creation of transmural lesion are known to be contact force, ablation time, power, etc. and force-time integral and ablation index have been used as a lesion quality marker. Optimal contact force is achievable when the appropriate catheter stability is maintained, so the contact force monitoring has been introduced into the current catheter technology. In general, contact force is low in anterior segments of LSPV and LIPV (ridge), inferior segments of LIPV, and posterior and inferior segments of RIPV [33, 34]. Therefore, it might be possible that catheter stability during the index procedure affect the results in the present study.

Our thickness map visualized prominent myofibers in the present study. They were compatible with their known locations. The clinical meaning of their existence was not demonstrated in this study, but thickness map could provide helpful information to physicians in creating linear ablation lesion in a particular area.
The design of the present study was retrospective, which limits data interpretation and clinical application. Among the enrolled patients, 19\% $(n=15)$ of index ablation procedures were performed in other institutions. Hence, a prospective study, such as using a tailored approach of PV isolation with thicknessdependent setting of RF energy delivery, is necessary to obtain robust evidence.

\section{Conclusion}

The reconnected segments of the PV antrum showed thicker myocardium than non-reconnected ones in patients with recurrent AF after catheter ablation. The use of wall thickness map for PV isolation could be considered for customized ablation in order to reduce PV reconnection.

\section{Abbreviations}

3D: Three-dimensional; AF: Atrial fibrillation; AWT: Atrial wall thickness; CT: Computed tomography; HU: Hounsfield units; LA: Left atrium; LIPV: Left inferior pulmonary vein; $L P V$ : Left pulmonary vein; $L S P V$ : Left superior pulmonary vein; PV: Pulmonary vein; RF: Radiofrequency; RIPV: Right inferior pulmonary vein; ROI: Region of interest; RPV: Right pulmonary vein; RSPV: Right superior pulmonary vein

\section{Acknowledgements}

None.

\section{Authors' contributions}

SO contributed to conception and design of the work; SO, EL, and WL contributed to acquisition, analysis, or interpretation of data; $\mathrm{SO}, \mathrm{YHJ}$, and $\mathrm{JCL}$ contributed to creation of new software used in the work; $\mathrm{SO}, \mathrm{YHJ}$, and WL contributed to writing draft; SO, SRL, MJC, and EKC contributed to critical revision of the manuscript. All authors have approved the submitted version and have agreed both to be personally accountable for the author's own contributions and to ensure that questions related to the accuracy or integrity of any part of the work.

Funding

The three-dimensional left atrial wall thickness map developed in this research was supported by the Bio \& Medical Technology Development Program of the National Research Foundation, which was funded by the Ministry of Science \& ICT, Republic of Korea (Grant No. 2015M3A9B6029139).

\section{Availability of supporting data}

No agreement on data release.

\section{Declarations}

Ethical Approval and Consent to participate

This study received approval from the Institutional Review Board at Seoul National University Hospital (IRB no. 1908-033-1052) and adhered to the guidelines set in the Declaration of Helsinki (2013). The study protocol was waived from informed consent for the study population owing to the retrospective nature of the study by the Institutional Review Board at Seoul National University Hospital.

Consent for publication

Not applicable. 


\section{Competing interests}

SO, YHJ, EL, SRL, MJC, JCL, WL declare that there is no conflict of interest relevant to the submitted work. EKC received a research grant not relevant to the submitted work from Biosense Webster.

\section{Author details}

${ }^{1}$ Department of Internal Medicine, Seoul National University College of Medicine and Seoul National University Hospital, 101 Daehak-ro, Jongno-gu, 03080 Seoul, Republic of Korea. ${ }^{2}$ Interdisciplinary Program in Bioengineering, Seoul National University, Seoul, Korea. ${ }^{3}$ Department of Biomedical Engineering, Seoul National University College of Medicine, Seoul, Korea. ${ }^{4}$ Department of Radiology, Seoul National University Hospital, Seoul, Korea.

Received: 16 July 2021 Accepted: 8 August 2021

Published online: 06 October 2021

\section{References}

1. Iwasaki YK, Nishida K, Kato T, Nattel S. Atrial fibrillation pathophysiology: implications for management. Circulation. 2011;124:2264-74.

2. Haissaguerre M, Jais P, Shah DC, Takahashi A, Hocini M, Quiniou G, Garrigue S, Le Mouroux A, Le Metayer P, Clementy J. Spontaneous initiation of atrial fibrillation by ectopic beats originating in the pulmonary veins. $\mathrm{N}$ Engl J Med. 1998;339:659-66.

3. Calkins H, Hindricks G, Cappato R, Kim YH, Saad EB, Aguinaga L, Akar JG, Badhwar V, Brugada J, Camm J, Chen PS, Chen SA, Chung MK, Nielsen JC, Curtis AB, Davies DW, Day JD, d'Avila A, de Groot N, Di Biase L, Duytschaever M, Edgerton JR, Ellenbogen KA, Ellinor PT, Ernst S, Fenelon G, Gerstenfeld EP, Haines DE, Haissaguerre M, Helm RH, Hylek E, Jackman WM, Jalife J, Kalman JM, Kautzner J, Kottkamp H, Kuck KH, Kumagai K, Lee R, Lewalter T, Lindsay BD, Macle L, Mansour M, Marchlinski FE, Michaud GF, Nakagawa H, Natale A, Nattel S, Okumura K, Packer D, Pokushalov E, Reynolds MR, Sanders P, Scanavacca M, Schilling R, Tondo C, Tsao HM, Verma A, Wilber DJ, Yamane T. 2017 HRS/EHRA/ECAS/APHRS/SOLAECE expert consensus statement on catheter and surgical ablation of atrial fibrillation. Heart Rhythm. 2017;14:e275-444.

4. Verma A, Kilicaslan F, Pisano E, Marrouche NF, Fanelli R, Brachmann J, Geunther J, Potenza D, Martin DO, Cummings J, Burkhardt JD, Saliba W, Schweikert RA, Natale A. Response of atrial fibrillation to pulmonary vein antrum isolation is directly related to resumption and delay of pulmonary vein conduction. Circulation. 2005:112:627-35.

5. Jais P, Cauchemez B, Macle L, Daoud E, Khairy P, Subbiah R, Hocini M, Extramiana F, Sacher F, Bordachar P, Klein G, Weerasooriya R, Clementy J, Haissaguerre M. Catheter ablation versus antiarrhythmic drugs for atrial fibrillation: the A4 study. Circulation. 2008;118:2498-505.

6. Eitel C, Hindricks G, Sommer P, Gaspar T, Kircher S, Wetzel U, Dagres N, Esato M, Bollmann A, Husser D, Hilbert S, Zaker-Shahrak R, Arya A, Piorkowski C. Circumferential pulmonary vein isolation and linear left atrial ablation as a single-catheter technique to achieve bidirectional conduction block: the pace-and-ablate approach. Heart Rhythm. 2010;7:157-64.

7. Macle L, Khairy P, Weerasooriya R, Novak P, Verma A, Willems S, Arentz T, Deisenhofer I, Veenhuyzen G, Scavee C, Jais P, Puererfellner $H$, Levesque S, Andrade JG, Rivard L, Guerra PG, Dubuc M, Thibault B, Talajic M, Roy D, Nattel $S$, investigators At. Adenosine-guided pulmonary vein isolation for the treatment of paroxysmal atrial fibrillation: an international, multicentre, randomised superiority trial. Lancet. 2015;386:672-9.

8. Wakasa S, Kubota S, Shingu Y, Kato H, Ooka T, Tachibana T, Matsui Y. Histological assessment of transmurality after repeated radiofrequency ablation of the left atrial wall. Gen Thorac Cardiovasc Surg. 2014;62:428-33.

9. Beinart R, Abbara S, Blum A, Ferencik M, Heist K, Ruskin J, Mansour M. Left atrial wall thickness variability measured by CT scans in patients undergoing pulmonary vein isolation. J Cardiovasc Electrophysiol. 2011;22:1232-6

10. Hayashi H, Hayashi M, Miyauchi Y, Takahashi K, Uetake S, Tsuboi I, Yodogawa K, Iwasaki YK, Shimizu W. Left atrial wall thickness and outcomes of catheter ablation for atrial fibrillation in patients with hypertrophic cardiomyopathy. J Interv Card Electrophysiol. 2014;40:153-60.

11. Cho Y, Lee W, Park EA, Oh IY, Choi EK, Seo JW, Oh S. The anatomical characteristics of three different endocardial lines in the left atrium: evaluation by computed tomography prior to mitral isthmus block attempt. Europace. 2012;14:1104-11.

12. Scherr D, Derval N, Sohal M, Pascale P, Wright M, Jadidi A, Komatsu $Y$, Roten L, Wilton SB, Pedersen M, Ramoul K, Miyazaki S, Shah A, Linton N, Manninger M, Denis A, Hocini M, Sacher F, Haissaguerre M, Jais P, Knecht S. Length of the mitral isthmus but not anatomical location of ablation line predicts bidirectional mitral isthmus block in patients undergoing catheter ablation of persistent atrial fibrillation: a randomized controlled trial. J Cardiovasc Electrophysiol. 2015;26:629-34.

13. Latcu DG, Squara F, Massaad Y, Bun SS, Saoudi N, Marchlinski FE. Electroanatomic characteristics of the mitral isthmus associated with successful mitral isthmus ablation. Europace. 2016;18:274-80.

14. Knecht S, Hocini M, Wright M, Lellouche N, O'Neill MD, Matsuo S, Nault I, Chauhan VS, Makati KJ, Bevilacqua M, Lim KT, Sacher F, Deplagne A Derval N, Bordachar P, Jais P, Clementy J, Haissaguerre M. Left atrial linear lesions are required for successful treatment of persistent atrial fibrillation. Eur Heart J. 2008;29:2359-66.

15. Jais P, Hocini M, Hsu LF, Sanders P, Scavee C, Weerasooriya R, Macle L, Raybaud F, Garrigue S, Shah DC, Le Metayer P, Clementy J, Haissaguerre M. Technique and results of linear ablation at the mitral isthmus. Circulation. 2004;110:2996-3002.

16. Takahashi K, Okumura Y, Watanabe I, Nagashima K, Sonoda K, Sasaki N, Kogawa R, Iso K, Ohkubo K, Nakai T, Hirayama A. Relation between left atrial wall thickness in patients with atrial fibrillation and intracardiac electrogram characteristics and ATP-provoked dormant pulmonary vein conduction. J Cardiovasc Electrophysiol. 2015;26:597-605.

17. Iso K, Okumura Y, Watanabe I, Nagashima K, Sonoda K, Kogawa R, Sasaki N, Takahashi K, Kurokawa S, Nakai T, Ohkubo K, Hirayama A. Wall thickness of the pulmonary vein-left atrial junction rather than electrical information as the major determinant of dormant conduction after contact force-guided pulmonary vein isolation. J Interv Card Electrophysiol. 2016;46:325-33.

18. Inoue J, Skanes AC, Gula LJ, Drangova M. Effect of Left Atrial Wall Thickness on Radiofrequency Ablation Success. J Cardiovasc Electrophysiol. 2016:27:1298-303.

19. Nakatani Y, Sakamoto T, Yamaguchi Y, Tsujino Y, Kataoka N, Kinugawa K. Heterogeneity in the left atrial wall thickness contributes to atrial fibrillation recurrence after catheter ablation. Heart Vessels. 2018;33:1549-58.

20. Cha MJ, Choi EK, Oh S. Comparison between local and systemic injection of adenosine for detecting dormant conduction after PV isolation. Pacing Clin Electrophysiol. 2017;40:762-9.

21. Moon I, Lee SY, Lee E, Lee SR, Cha MJ, Choi EK, Oh S. Extensive left atrial ablation was associated with exacerbation of left atrial stiffness and dyspnea. J Cardiovasc Electrophysiol. 2019;30:2782-9.

22. Lee SR, Choi EK, Lee EJ, Choe WS, Cha MJ, Oh S. Efficacy of the optimal ablation index-targeted strategy for pulmonary vein isolation in patients with atrial fibrillation: the OPTIMUM study results. J Interv Card Electrophysiol. 2019;55:171-81.

23. Arenal A, Atea L, Datino T, Gonzalez-Torrecilla E, Atienza F, Almendral J, Sanchez A, Sanchez PL, Fernandez-Aviles F. Identification of conduction gaps in the ablation line during left atrium circumferential ablation: facilitation of pulmonary vein disconnection after endpoint modification according to electrogram characteristics. Heart Rhythm. 2008;5:994-1002.

24. Bishop M, Rajani R, Plank G, Gaddum N, Carr-White G, Wright M, O'Neill M, Niederer S. Three-dimensional atrial wall thickness maps to inform catheter ablation procedures for atrial fibrillation. Europace. 2016;18:376-83.

25. Ho SY, Sanchez-Quintana D. The importance of atrial structure and fibers. Clin Anat. 2009:22:52-63.

26. Pashakhanloo F, Herzka DA, Ashikaga H, Mori S, Gai N, Bluemke DA, Trayanova NA, McVeigh ER. Myofiber Architecture of the Human Atria as Revealed by Submillimeter Diffusion Tensor Imaging. Circ Arrhythm Electrophysiol. 2016;9:e004133.

27. Suenari K, Nakano Y, Hirai Y, Ogi H, Oda N, Makita Y, Ueda S, Kajihara K, Tokuyama T, Motoda C, Fujiwara M, Chayama K, Kihara Y. Left atrial thickness under the catheter ablation lines in patients with paroxysmal atrial fibrillation: insights from 64-slice multidetector computed tomography. Heart Vessels. 2013;28:360-8.

28. Takigawa M, Yamada T, Yoshida Y, Ishikawa K, Aoyama Y, Yamamoto T, Inoue N, Tatematsu Y, Nanasato M, Kato K, Tsuboi N, Hirayama H. The incidence and clinical significance of non-isolation of the pulmonary vein 
carina after encircling ipsilateral pulmonary veins isolation for paroxysmal atrial fibrillation: a pitfall of the double-Lasso technique. Europace. 2013;15:33-40.

29. Kumagai K, Naito S, Nakamura K, Hayashi T, Fukazawa R, Sato C, Takemura N, Miki Y, Fuke E, Tanaka Y, Hori Y, Goto K, Iwamoto J, Aonuma K, Oshima S, Taniguchi K. ATP-induced dormant pulmonary veins originating from the carina region after circumferential pulmonary vein isolation of atrial fibrillation. J Cardiovasc Electrophysiol. 2010;21:494-500.

30. Aubrey J, Esfandiari N, Baracos VE, Buteau FA, Frenette J, Putman CT, Mazurak VC. Measurement of skeletal muscle radiation attenuation and basis of its biological variation. Acta Physiol (Oxf). 2014;210:489-97.

31. Rodriguez-Granillo GA, Rosales MA, Degrossi E, Rodriguez AE. Signal density of left ventricular myocardial segments and impact of beam hardening artifact: implications for myocardial perfusion assessment by multidetector CT coronary angiography. Int J Cardiovasc Imaging. 2010;26:345-54

32. Varela M, Morgan R, Theron A, Dillon-Murphy D, Chubb H, Whitaker J, Henningsson M, Aljabar P, Schaeffter T, Kolbitsch C, Aslanidi OV. Novel MRI technique enables non-invasive measurement of atrial wall thickness. IEEE Trans Med Imaging. 2017;36:1607-14.

33. Makimoto H, Lin T, Rillig A, Metzner A, Wohlmuth P, Arya A, Antz M, Mathew S, Deiss S, Wissner E, Rausch P, Bardyszewski A, Kamioka M, Li X, Kuck KH, Ouyang F, Tilz RR. In vivo contact force analysis and correlation with tissue impedance during left atrial mapping and catheter ablation of atrial fibrillation. Circ Arrhythm Electrophysiol. 2014;7:46-54.

34. Schluermann F, Krauss T, Biermann J, Hartmann M, Trolese L, Pache G, Bode C, Asbach S. In vivo contact force measurements and correlation with left atrial anatomy during catheter ablation of atrial fibrillation. Europace. 2015;17:1526-32.

\section{Publisher's Note}

Springer Nature remains neutral with regard to jurisdictional claims in published maps and institutional affiliations.
Ready to submit your research? Choose BMC and benefit from:

- fast, convenient online submission

- thorough peer review by experienced researchers in your field

- rapid publication on acceptance

- support for research data, including large and complex data types

- gold Open Access which fosters wider collaboration and increased citations

- maximum visibility for your research: over 100M website views per year

At BMC, research is always in progress.

Learn more biomedcentral.com/submissions 